\title{
Mathematical Modeling of Teacher-Student Relationship
}

\author{
Baosen $\mathrm{Xiao}^{\mathrm{a}}$, Kai Kang ${ }^{\mathrm{b}, *}$
}

\author{
School of Information Science \& Technology, Xiamen University Tan Kah Kee College, Xiamen, \\ China \\ axbsxmu@xujc.com, ${ }^{b}$ kangkai@xujc.com
}

Keywords:college, education, expectation, relationship.

\begin{abstract}
Teacher-student relationship is an important part of teaching activities. College education is not a simple process of teaching and learning. It requires more communication between teachers and students. There are many negative factors which are affecting the teacher-student relationship in real life. The article describes several important factors (the impact of network, policies and evaluation system for teachers, too high expectation of students, too high expectation of teachers), and analyzes their functional relationship with teacher-student relationship. We can vividly see the relationship between them by building mathematical modeling. Then author puts forwardsome recommendations to improve the teacher-student relationship. Establishing harmonious relationship between teachers and students needs the efforts from teachers and students, the efforts from schools and society.
\end{abstract}

\section{Introduction}

As an educator, the teacher is an important force, and plays the role of a bridge in human social continuation and development. In China, people see a teacher as a noble and sacred figure. Therefore, though we emphasize we should respect teachers and love students. But in fact, teachers often enjoy their respect from students. As an educated, students obey teachers with lowliness. The relationship between teachers and students is distorted in the influence of 'master and apprentice just look like father and son', especially under the heavy pressure of examination-oriented education [1].

The key factors of limiting the development of college education are not just teachers' teaching ability and teaching method, the biggest obstacle is the relationship between teachers and students. Colleges are charged with task of cultivating the successors with modern awareness and innovative consciousness of socialist modernization [2]. The relationship between college teachers and students is one of the most important relations in colleges. The relationship should be a new type of harmonious, democratic and equal relation. However, today, the relationship between Chinese college teachers and students isn't so good. The paper does the analysis on the affecting factors of college teachers and students, and finds out the main reasons are from society, college, teachers and students four aspects. The study hopes to do some promotion of constructing harmonious relationship between college teachers and students.

\section{Background}

At present, it's a cold knowledge transfer process usually in college teaching. Some teachers stand on the platform with no expression, read the script dull. Students listen blankly. The end of course, teachers take his books and go away. Because of seldom equal exchange between teachers and students, the indifferent teacher-student relationship is formed.

In fact, college education is not a simple process of teaching and learning. It requires communication between teachers and students. Affected by the market economy, the relationship between teachers and students in universities has changed. Master students usually call mentors as boss in universities, the title change reflects current teacher-student relationship tend to be utilitarian. Master students need mentors to provide project and funding for them, which is enable to help them complete papers and get a degree; mentors need students take on projects, and be a member labor of 
the project team. The system of university should be reformed to get rid of the utilitarian, re-design and develop the teacher-student relationship [3].

\section{Factors of affecting teacher-student relationship}

Current college teacher-student relation can't be ignored. Building harmonious teacher-student relationship has become the current higher education object to be reached. Now, we do a little analysis on the teacher-student relationship in China.

3.1 The impact of network. The original multimedia as a teaching adjunct replaces the traditional classroom teaching mode. Traditional teaching mainly relies on writing on the blackboard with chalk. It can bring more communication chance to teachers and students.

Taking multimedia presentation PowerPoint(PPT) to teach could not only expand lesson capacity but also increase the teaching interesting for its illustration. But some teachers show over-reliance on the PPT teaching, regardless of the students who accept knowledge or not. So, the students' desire to communicate with teachers is reducing slowly. Networks bring much convenience to us, but also bring many negative effects. Even worse, if college students addict to the Internet, they will become solitary and are not unwilling to communicate with other students and teachers. In this network age, the way to access knowledge is diverse, students no longer rely on teachers solely. Widening the distance between teachers and students, the teacher-student relationship will alienate.

3.2 Policies and evaluation system for teachers. The teachers need not only to explain "missionary" and "doubts", impart knowledge, but also show an example for students in the ethics, morality and personality. In China, university tuition is a little expensive. Compared to the $1980 \mathrm{~s}$, it is no longer free now. Students believe that they should receive something from colleges and teachers after paying the tuition with self-employment. Colleges charge tuition, teachers receive salary. Students think colleges and teachers do nothing for themselves. Thus there is a lack of deep emotional basis between teachers and students. The current unreasonable evaluation system is the main reason. Moreover, the university evaluation system for teachers makes colleges and teachers ignore the importance of the teacher-student relationship. The relationship of teachers and students is not taken into the assessment for teachers. Under the heavy pressure of research, many teachers spend most of time on research, naturally have not enough time and energy for the exchanges of teachers and students [4].

3.3 Too high expectation to students. Some college teachers believe that college students as an adult should cherish the opportunity to learn, should be independent, should study hard, should not act like pupils. Teachers may require students to do that or not do that, neglect a fact that students have their own ideas. Contradictions between teachers and students gradually formed.

3.4 Too high expectation to teachers.Most students think that university teachers should be knowledgeable, full of rich teaching experience. They find that schools, teachers and many things are not so good in minds after coming into the university with vision and worship. No one is perfect. College teachers are not God, they are impossible stronger than students in every aspect.

So, there are eight possible relationships between teachers and students.
( I ) Friends
( II ) Competitors
(III) Strangers
(IV) Parent-child
(V) Teaching and learning
(VI) Boss-employee
(VII) Enemy
(VIII) Romantic 


\section{Models}

The discussion above mainly analyzes factors that influence the relationship between teachers and students from four aspects of social factors(conceptual change, the impact of network), school factors(policies and evaluation system for teachers), teacher factors(too high expectation of students) and student factors(too high expectation of teachers). Because of many other factors, I intend to select the four important and representative factors described above as variables, and analysis that how these four factors affect the relationship between teachers and students in details. The four variables are: $\mathrm{a}=$ the impact of network development, $\mathrm{b}=$ policies and evaluation system for teachers, $\mathrm{c}=$ too high expectation of students, $\mathrm{d}=$ too high expectation of teachers.

Assuming that the relationship of teachers and students is $\mathrm{F}$, and there is a following relationship: $\mathrm{F}=\mathrm{F}_{1}+\mathrm{F}_{2}+\mathrm{F}_{3}+\mathrm{F}_{4}$, teacher-student relationship component $\mathrm{F}_{1}=\mathrm{f}_{1}(\mathrm{a})$, teacher-student relationship component $\mathrm{F}_{2}=\mathrm{f}_{2}(\mathrm{~b})$, teacher-student relationship component $\mathrm{F}_{3}=\mathrm{f}_{3}(\mathrm{c})$, teacher-student relationship component $\mathrm{F}_{4}=\mathrm{f}_{4}(\mathrm{~d})$. The range of $\mathrm{F}$ varies from 0 to 100 . The larger $\mathrm{F}$ value is, the more reasonable 4 variables consisted of $\mathrm{a}, \mathrm{b}, \mathrm{c}$ and $\mathrm{d}$ are, the relationship of teachers and students is more harmonious and friendly. On the contrary, if $F$ value is smaller, it implies that structure of $a, b, c, d$ is more unreasonable, the relationship of teachers and students is worse and more tension, it should cause a alarm. Taking into account that $\mathrm{a}, \mathrm{b}, \mathrm{c}$ and d play a different effect in the teacher-student relationship $\mathrm{F}$, and their operability are different, assigning different weights for $\mathrm{F}_{1}, \mathrm{~F}_{2}, \mathrm{~F}_{3}, \mathrm{~F}_{4}: \mathrm{F}_{1}=20, \mathrm{~F}_{2}=30$, $F_{3}=25, F_{4}=25$. In my opinion, the allocation ratio of $F_{1}, F_{2}, F_{3}, F_{4}$ is reasonable.

Now, let me take an analysis for the four variables.

(A)The function of network development and teacher-student relationship component $F_{1}: F_{1}=f_{1}(a)$

As mentioned above: The original multimedia as a teaching adjunct replaces the traditional classroom teaching mode. Cold machines also reduce the relationship between teachers and students in its temperature and enthusiasm. Some teachers show over-reliance on the PPT teaching, regardless of the students who accept knowledge or not. They just read the script facing the PPT and rarely interact with students, it will affect the teacher-student relationship inevitably. In addition, the development of network result in a phenomenon that a part of college students indulge in the network, which lead to their weakening of face-to-face exchanges needs to other people around. Therefore, knowledge channels are broadening, while the door of communication is narrowing, the distance between teacher-student is enlarging. To a certain extent, the relationship between teachers and students become alienated.

Based on the above, I know that $\mathrm{F}_{1}$ is inversely proportional to a. With the continuous development of the network, $\mathrm{F}_{1}$ becomes more and more lower, but it will not be 0 , it will approach a constant, the reasonable value is assumed to be 5. So I set up the following functional relationship.

$$
=\mathrm{f}(\mathrm{a})=
$$

(a

The curve of F1-a is shown in Figure 1.

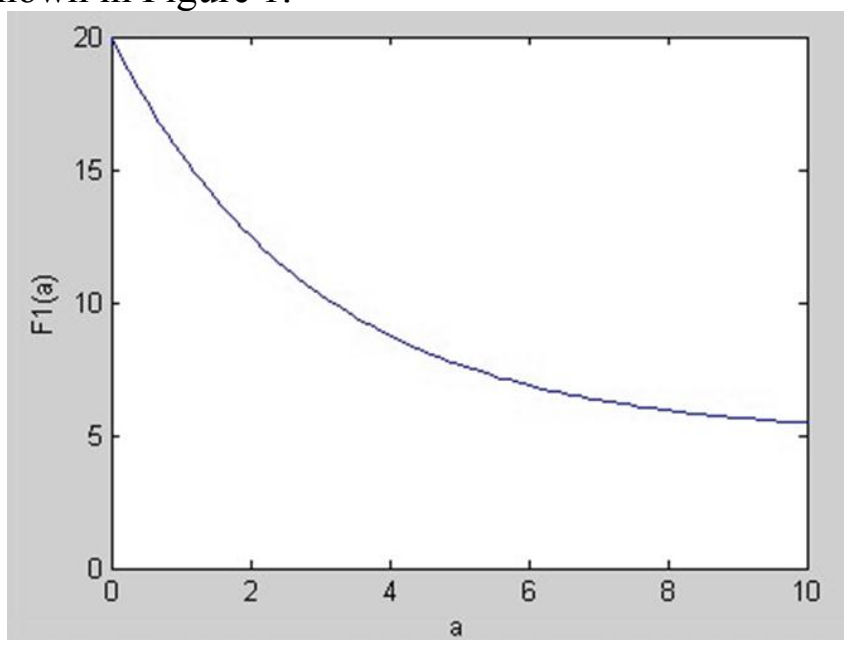

Fig.1 F1-a relationship diagram

From Figure 1, we can see visually, on non-network period, that is, $a=0$, the teacher-student relationship component F1 take the maximum 20. With the continuous development of the network, the network plays a growing impact on F1, F1 value become smaller and smaller. F1 value is close to 
5 at last. Of course, if we can treat the development of network with the right attitude and thinking, and make full use of the advantages of the network itself, then the teacher-student relationship component $\mathrm{F} 1$ can be maintained at a higher value.

(B)The function of policies, evaluation system for teachers and teacher-student relationship component $\mathrm{F}_{2}: \mathrm{F}_{2}=\mathrm{f}_{2}(\mathrm{~b})$

Currently, many colleges implement quantitative assessment which inclines to research seriously. Teachers' title enhance and income are relative to the evaluation. In the appraisal system, the responsibilities of educating students have been challenged.

Policies and evaluation system for teachers is an important and complex work. It is relative to many factors, and some factors cannot be judged accurately. Rational policies and evaluation system for teachers will give teachers more time and space, thus, they don't focus on the scientific research. Naturally, teachers will have enough time and energy to communicate with students. If so, the value of teacher-student relationship component $F_{2}$ will reach a high point. On the contrary, the value of $F_{2}$ will be in a low level if teachers are busy doing research or writing essay. The importance of making a rational policies and evaluation system for teachers goes without saying. Now I discuss the function of policies , evaluation system for teachers and teacher-student relationship component $\mathrm{F}_{2}$ regardless that how to develop a reasonable system.

In the formula: $F_{2}=f_{2}(b),\left(0 \leq b \leq 1, F_{2} \leq 30\right)$, variable $b$ stands for the tightness of management system and evaluation system. The lower the value of $b$ is, the looser the policies and evaluation system for teachers is. The higher the value of $b$ is, the more tightly the policies and evaluation system for teachers is. It is not well for $F_{2}$ if the value of $b$ is too low or too high. I assume that the best value of $b$ is 0.5 . And there are reasons to believe that $F_{2}-b$ curve is roughly in line with the probability density function of normal distribution.Here is the function, with $u$ represents mean, $\sigma^{2}$ reoresents variance

$$
\mathrm{f}(\mathrm{x} ; \mu, \sigma)=\frac{1}{\sigma \sqrt{2 \pi}} \exp \left(-\frac{(\mathrm{x}-\mu)^{2}}{2 \sigma^{2}}\right)
$$

Let $\mathrm{u}=0.5, \sigma=0.2, \mathrm{f}-\mathrm{x}$ curve is shown as the following.

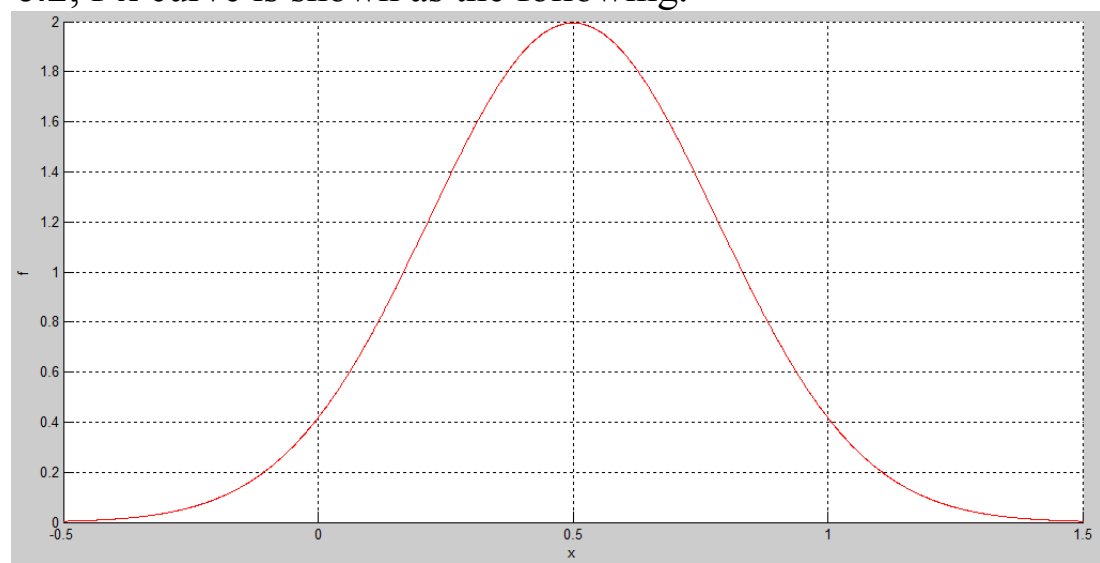

Fig. 2 f-x relationship diagram

From the above diagram, we can clearly see that the maximum of $\mathrm{f}$ is 2 , its symmetric axis is 0.5 . The value range of $\mathrm{f}$ is $0-1$ after be divided by 2 .

On the basis of the above analysis, I set up the following functional relationship.

$$
F_{2}=\mathrm{f}_{2}(\mathrm{~b})=30 \times \frac{1}{2} \times \mathrm{f}(\mathrm{b} ; \mu, \sigma)=\frac{15}{\sigma \sqrt{2 \pi}} \exp \left(-\frac{(\mathrm{b}-\mu)^{2}}{2 \sigma^{2}}\right) \quad(\mu=0.5, \sigma=0.2)
$$




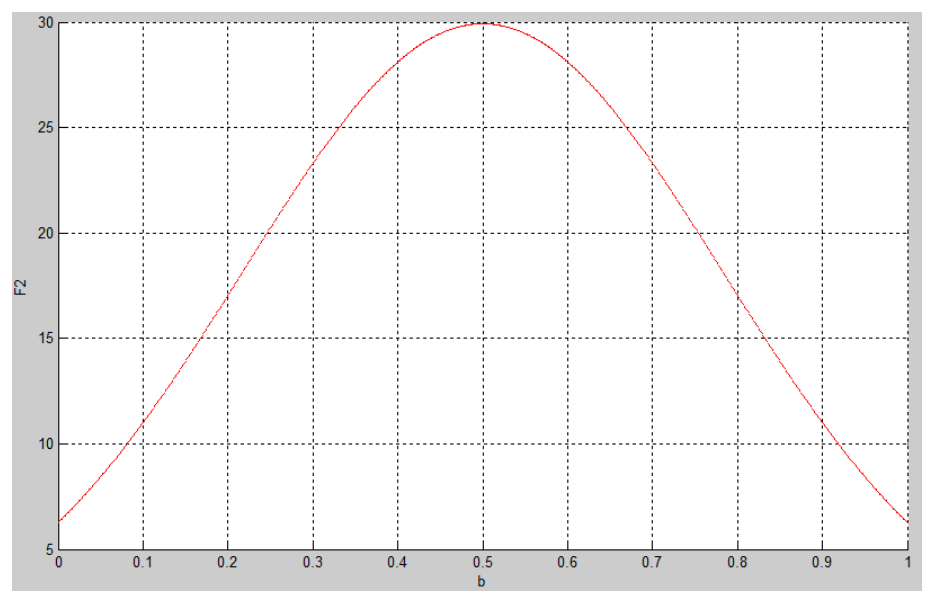

Fig. $3 \mathrm{~F}_{2}-\mathrm{b}$ relationship diagram

(C)The function of expectation of students $(=\mathrm{c})$, expectation of teachers $(=\mathrm{d})$ and teacher-student relationship component $\mathrm{F}_{3}$ and component $\mathrm{F}_{4}: \mathrm{F}_{3}=\mathrm{f}_{3}(\mathrm{c}), \mathrm{F}_{4}=\mathrm{f}_{4}(\mathrm{~d})$

We know that expectation of students and expectation of teachers are influencing each other. If expectation of teachers to students is high, expectation of students to teachers is high naturally. Similarly, if expectation of teachers to students is low, students will not show high expectation of teachers, too. Let $F_{0}=F_{3}+F_{4}=f_{3}(c)+f_{4}(d)$. From the information of page 5, I conclude the following equation.

$$
F_{0}=F_{3}+F_{4}=f_{3}(c)+f_{4}(d) \leq 50 \quad\left(f_{3}(c) \leq 25, f_{4}(d) \leq 25\right)
$$

The range of $\mathrm{c}$ and $\mathrm{d}$ both varies from 0 to 1 . So there are the two following inequalities.

$$
0 \leq \mathrm{c} \leq 1,0 \leq \mathrm{d} \leq 1
$$

The value of expectation (no matter of teachers, or of students) will affect $\mathrm{F}_{0}$ directly. The value of $f_{3}(c)$ is influenced by $f_{4}(d)$. Of course, the value of $f_{4}(d)$ is influenced by $f_{3}(c)$. As is known to all, the more expectation of teachers is, the more expectation of students is. The more expectation of students is, the more expectation of teachers is, too. Generally speaking, in the condition of $\Delta \mathrm{c}=$ $\Delta \mathrm{d}, \Delta \mathrm{f}_{3}(\mathrm{c})<\Delta \mathrm{f}_{4}(\mathrm{~d})$. It means that the value of expectation of teachers is a little more easily affected. We can write

$$
\frac{\partial \mathrm{f}_{4}}{\partial \mathrm{f}_{3}}=\frac{\mathrm{f}_{4}(\mathrm{x}+\Delta)-\mathrm{f}_{4}(\mathrm{x})}{\mathrm{f}_{3}(\mathrm{x}+\Delta)-\mathrm{f}_{3}(\mathrm{x})}>0
$$

This means $\mathrm{f}_{3}(\mathrm{c})$ and $\mathrm{f}_{4}(\mathrm{~d})$ are in a direct basic proportion relationship. The trend of the curve of $\mathrm{f}_{3}(\mathrm{c})$ and $\mathrm{f}_{4}(\mathrm{~d})$ is roughly the same. We can also obtain one of constraints which is $\mathrm{d}=1.2 \mathrm{c}$.

It is not good for the development of teacher-student relationship, if the value of expectation (no matter of teachers, or of students) is too high or too low. The value of expectation which is high means that teachers or students should do more better to satisfy the demand of students or teachers. The value of expectation which is low means that teachers or students don't have enough power to work or study, it is also unfavorable to the development of the relationship between teachers and students.

When does $\mathrm{F}_{3}$ or $\mathrm{F}_{4}$ reach the maximum value, what is the trend of the curve? This is a worthy of further discussion. Assuming that $\mathrm{F}_{3}$ meets the relationship of quadratic function, we can write

$$
\mathrm{F}_{3}=\mathrm{f}_{3}(\mathrm{c})=-\mathrm{k} \times(\mathrm{c}-\mathrm{t})^{2}+25
$$

Now, let $\mathrm{t}=0.5$ be the constraint such that $\mathrm{F}_{3}$ is maximized. Assuming that the minimum of $\mathrm{F}_{3}$ is 7 , not 0 . It is easy to obtain the following function.

$$
\begin{gathered}
\mathrm{F}_{3}=\mathrm{f}_{3}(\mathrm{c})=-64 \times(\mathrm{c}-0.5)^{2}+25 \\
\mathrm{~F}_{4}=\mathrm{f}_{4}(\mathrm{~d})=-64 \times(\mathrm{d}-0.5)^{2}+25
\end{gathered}
$$




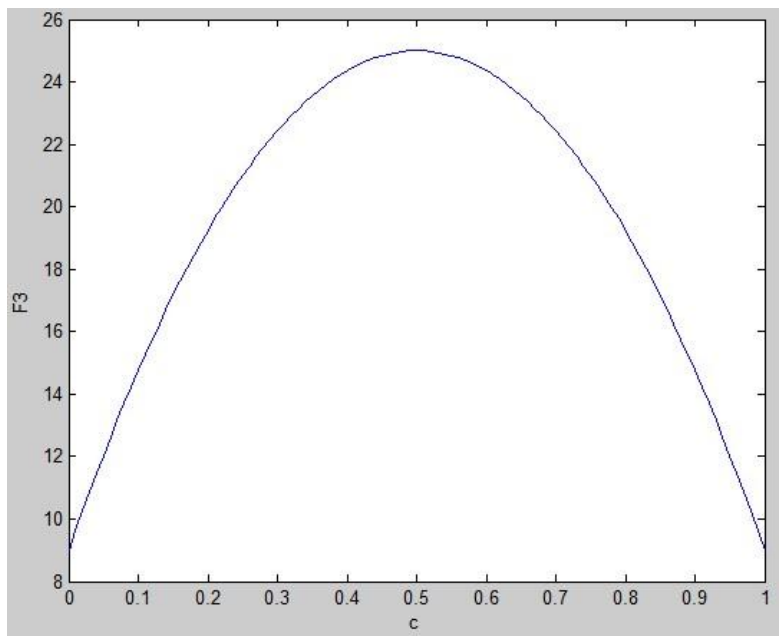

Fig.4 F3- c relationship diagram

From Figure 4, teachers should spend their time on communicating with students, understanding students, and don't give students too much pressure. Similarly, students must know that no one is perfect. College teachers are inadequacies, of course, especially in the era of information network, the sources of knowledge and ideal diversify, teachers are impossible stronger than students in every aspect. So colleges should call for teaching and learning grow together in the teacher- student relationship. If so, the teacher-student relationship will be harmonious. It is beneficial to both teachers and students.

In summary, $F=F_{1}+F_{2}+F_{3}+F_{4}=f 1(a)+f_{2}(b)+f_{3}(c)+f_{4}(d)$

$=15 \times 2^{-\frac{1}{2} \mathrm{a}}+5+\frac{15}{0.2 \sqrt{2 \pi}} \exp \left(-\frac{(\mathrm{b}-0.5)^{2}}{2 \cdot 0.2^{2}}\right)-64 \times(\mathrm{c}-0.5)^{2}+23-64 \times(\mathrm{d}-0.5)^{2}+23$

$=15 \times 2^{-\frac{1}{2} \mathrm{a}}+\frac{15}{0.2 \sqrt{2 \pi}} \exp \left(-\frac{(\mathrm{b}-0.5)^{2}}{2 \cdot 0.2^{2}}\right)-64 \times\left[(\mathrm{c}-0.5)^{2}+(\mathrm{d}-0.5)^{2}\right]+51$

---our improvement to be maximized

$\mathrm{d}=1.2 \mathrm{c} \quad---$ constrains $1(0 \leq \mathrm{c} \leq 0.9,0 \leq \mathrm{d} \leq 0.9)$

$\mathrm{a}=-8\left(\mathrm{~b}-\frac{1}{2}\right)^{2}+8--$ constrains $2(\mathrm{a} \geq 0,0 \leq \mathrm{b} \leq 0.9)$

$\mathrm{b}^{2}+2 \mathrm{c}^{2}=1 \quad--$ constrains 3

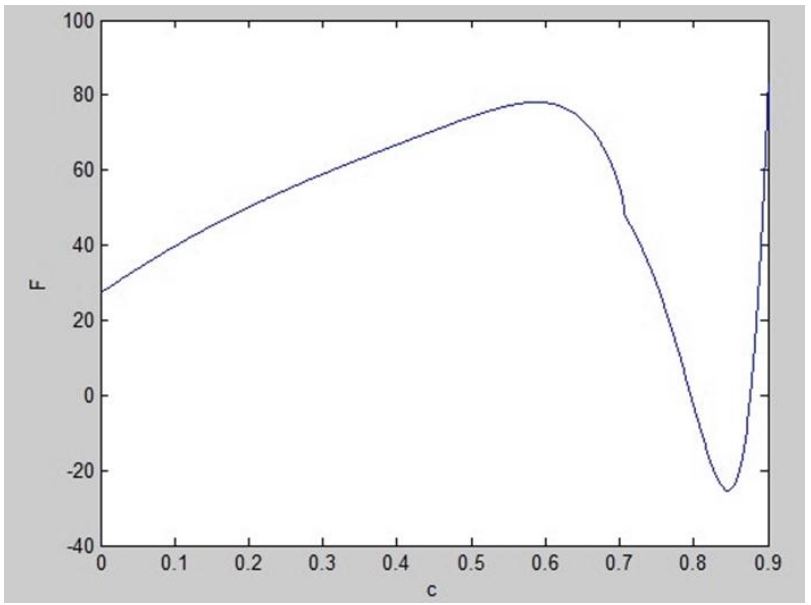

Fig. 5 F- c relationship diagram

Until now, we obtain the final equation Eq.(9). Eq.(9) reveals the connection among teacher-student relationship, the impact of network development, management system and evaluation system, too high expectation of students and too high expectation of teachers. From Figure 5, we can clearly see that the best value of $c$ is 0.6 , furthermore, we can obtain the best value: $a=7.6, b=0.53$, $\mathrm{d}=0.72$. On the basis of the value of $\mathrm{a}, \mathrm{b}, \mathrm{c}, \mathrm{d}$, the max value of $\mathrm{F}$ is 80 .

\section{Countermeasures}

Students are educated, and teachers are educators all the time. In the relationship between teachers 
and students, teachers are in the leading position. Therefore, the key to construct the harmonious relationship between teachers and students are teachers.

5.1 Abide by professional ethics.As a teacher, it is necessary to recognize that the pursuit of the objectives and results of education is reflected by the students, so teachers must establish the concept of student-centered [5]. First, for college teachers, they must have a brand new viewpoint. To clear, schools cultivate students, as long as they have certain professional skills to satisfy the production, construction is "talent", cannot see these students whose theory knowledge is not solid as worthless. Second, respect the individual differences of students. Every student has his own personality due to geographical, family, experience, academic achievement. Teachers must recognize the reality, teach students in accordance with their aptitude [6].

5.2 Students should establish correct ideas, correct learning attitude.Contemporary college students as the future of our motherland, will certainly shoulder the responsibility of national development. At the same time, the fierce competition which they face is also unprecedented in the time of developed knowledge economy. This requires our college students must set up the correct outlook on life and values, correct study manner, and train themselves into accord with the demands of the era of a new generation. The society and colleges should take responsibility actively, teachers and students should make positive joint efforts, and strengthen research, exchange and communication, to melt the gap between teachers and students with love and patience, build equality and harmonious relationship between teachers and students, develop more useful talents both having ability and political integrity for the society [7]. Nowadays, most of students have never born hardship. They even don't know what they can do in future and have not any future plan. In addition, the lack of guidance from parent is also the source of students' bad habits.

5.3 Comprehensive care for students.First, love students. As a teacher, we should treat students as one member of our family. They may do something as they like. Before entering university, students study in school, most of other times, they live with parents at home. So their independence is not mature. Parents also tell children what can do and what cannot do. It is not doubt that parents deeply love their children in their ways. Parents care that whether children is full, feel cold or not. They seldom know that children' independence is enough, can children adapt to the development of society? Parents mostly care that if their children' study is good enough. In fact, independence as one of the most characters plays an important role in a person's life [8]. After entering university, students have their space to do what they like, because they are far from parents, parents are not able to give much constraint to children. Students become more and more mature. But as a child, student knows little about society, and cannot take care of himself. As an educator, teacher should show concern to student.

Second, the concern to students is also presenting in the trust and respect of students. Every student has his own advantage and sparking. Teachers are good at discovering the students' strong suits, seizing every educational opportunity, praising and encouraging students timely. Poor students should be paid more attention to. It is no doubt that most of teachers love excellent students, and pay more time to them [9]. We should help poor students cultivate their confidence slowly.

5.4Establish a sense of democracy, take the initiative to communicate with students equally.Teachers should pay attention to establish equal and kindly relationship with students. As a student, he is expecting to be treated equally. Students hope that teachers can be their friends but not only teachers. In this way, students can chat with students if they have puzzle in study or life. Teachers who have more experience may give some useful and guiding suggestions to students. Establish democratic, equal and friendly relationship between teachers and students in the whole process of teaching. The basis of teachers' authority is not the status, but the knowledge, ability and moral of teachers. The best way to establish friendly relationship is joining in the activities of students. And express teachers' youth and vitality in activities [10].

5.5 Changing the teaching style. Teaching is the uniform combination between the teaching of teachers and the learning of students. Students obtain knowledge by the guidance of teachers. Everyone must have many teachers from primary school to university. Every teacher has his teaching style. Some maybe salt, some maybe serious. The teacher who can mobilize the learning atmosphere 
is popular with students.

If there is a system which allows students to evaluate the quality of teaching and learning activities, it will be beneficial to improve the classroom atmosphere and the relationship between teachers and students. The enthusiasm of participating in teaching from students will affect teachers' emoting in teaching. The communication and cooperation will be enhanced. Students think that they win the respect from teachers, they will show obvious love to teachers. Better effect will be shown if teachers take new teaching methods, such as video, discussion in group, et al., along with traditional methods. Students are the children who like to try new methods no matter in study or others.

Team learning is a basic form of learning in western universities, teachers organize team learning for each course, and even every class. In Chinese universities, team learning is just a secondary and not important method. In the learning of most of courses, college students are used to individual learning, such an individual preparation before class, listening to teachers in class and individual review after class. The individual learning is not conducive to the development of students' cognition and the development of students' emotion. We need to change the mere individual learning to cooperative learning in classroom teaching. The method of cooperative learning can be applied to problems which are difficult to be settled for one person, and also the problems can be solved entirely by one's own ability. The essence of cooperative learning is to build a collective, which enables students to become a member of the collective. Furthermore, they can discuss and solve problems from different point of views. Students who are in cooperative learning are capable of not only learning to know, but also learning to organize, learning to express, learning to tolerance and learning to live with different opinions of people in harmony.

The relationship of teachers and students are an eternal topic. We need to pay more attention and efforts to how to make the relationship of teachers and students more humanism. Teachers affect students by right of noble charisma, profound knowledge, students should understand that teachers not only teachers for solving questions, but also friends who can share their happiness and worry.

In short, the factors of affecting the relationship between teachers and students are so many and complex. Establishing harmonious relationship between teachers and students needs the efforts from teachers and students, the efforts from schools and society.

\section{References}

[1] NRC, Discipline-Based Education Research: Understanding and Improving Learning in Undergraduate Science and Engineering (National Academies Press, Washington, DC, 2012).

[2] E.F. Redish, J.M. Saul, and R.N. Steinberg, Student expectations in introductory physics, Am. J. Phys. 66, 212 (1998).

[3] Pawl, A. Barrantes, and D.E. Pritchard, Modeling applied to problem solving, AIP Conf. Proc. 1179, 51 (2009).

[4] S.J. Pollock, No single cause: Learning gains, student attitudes, and the impacts of multiple effective reforms, AIP Conf. Proc. 790, 137 (2005).

[5] E.J. Dixon-Roman, H.T. Everson, and J.J. McArdle, Race, Poverty and SAT Scores: Modeling the Influences of Family Income on Black and White High School Students SAT Performance, Teachers Coll. Rec. 115 (2013).

[6] L.R. Gay, G.E. Mills, and P.W. Airasian, Educational Research: Competencies for Analysis \& Applications (Prentice-Hall, Upper Saddle River, NJ, 2006), 8th ed.

[7] F. Reif, Millikan Lecture 1994: Understanding and teaching important scientific thought processes, Am. J. Phys. 63, 17 (1995).

[8] J.S. Eccles and A. Wigfield, Motivational beliefs, values and goals, Annu. Rev. Psychol. 53, 109 (2002).

[9] A. Orton, Students' understanding of integration, Educ. Stud. Math. 14, 1 (1983).

[10] K. Cummings, S. Lockwood, and J. D. Marx, Attitudes toward problem solving as predictors of student success, AIP Conf. Proc. 720, 133 (2004). 